\title{
Southern Division trainees' day
}

\author{
Dinesh BHugra, The Maudsley Hospital, Denmark Hill, London SE5 8AZ \\ (correspondence); Amanda PoYnTon, Guy's Hospital, London Bridge, \\ London SE1; and JAN FALKOWSKI, St George's Hospital, Tooting, London SW17
}

A trainees' day for the Southern Division of the Royal College of Psychiatrists was held at the Bethlem Royal Hospital, Beckenham on 8 March 1989. This was in parallel with the Southern Division meeting organised for the same day at the same venue. The joint meeting enabled a wider publicity of the trainees' day but may have affected the numbers of trainees attending on the day.

The programme for the trainees' day consisted of talks from three invited speakers, an introduction to the Collegiate Trainees' Committee and an opportunity to use computer based MCQs. A visit to the Bethlem museum was also available for those interested.

Professor R. H. Cawley (Professor of Psychological Medicine at King's College Hospital and Institute of Psychiatry) saw the introduction of the new examination and was thus well-placed to offer trainees insight into how to prepare for and pass the examination. Covering both parts of the examination, he gave a personal view of different techniques, knowledge and emphasis required for each examination, as well as the reading material currently available. Finally he discussed the problems of difficult patients and difficult examiners, providing some reassurance for future candidates.

Dr A. MacDonald, Senior Lecturer from Guy's Hospital Medical School, talked on 'How to do Research'. This was a lively overview of the topic; commenting on reasons for doing research, he suggested that these included the familiar situations of being faced with a problem, or desiring career advancement, or the less familiar such as a burning desire for the Nobel Prize. He gave a comprehensive account of types of research, the development and execution of research ideas and how to get results disseminated widely. Following this lecture the trainees joined their senior colleagues in the Southern Division meeting.
Dr J. Bolton, Clinical Tutor, St George's Medical School, addressed the trainees on the subject of 'How to get the job you really want'. He gave a penetrating yet amusing analysis of the importance of good presentation both of the curriculum vitae and of the self. He emphasised the need for preparation, by understanding the job description and pre-interview visits. The sound practical advice was of potential benefit for trainees at all stages of their careers.

The CTC representatives then took turns to explain the role of the CTC. This led to a lively discussion on various issues relevant to the trainees and some have subsequently been discussed in the CTC meetings. The trainees' day was evaluated using a short questionnaire. At the end of the day 15 questionnaires were returned ( $58 \%$ response rate), of which 11 were from inceptors and the others from non-inceptors. Eighty per cent had become aware of the day from the information circulated by the College. Few had experienced difficulties in reaching the venue. The general opinion of the meeting was positive $-80 \%$ describing it as good and $20 \%$ as adequate. The museum visit and MCQs on computers were taken up by nine and five respondents respectively. Nearly all respondents (13 out of 15 ) said they would definitely attend another meeting while one person was uncertain and another gave a definite no. Nearly half the trainees suggested that meetings should be held quarterly or more frequently whereas the rest thought that six monthly or once a year was adequate. Items of interest for future meetings included the White Paper, management training, Achieving a Balance, work load and conditions of service.

The responses from the questionnaires were limited to about half the trainees who attended, but they will enable us to plan future meetings and organise them better, with regular monitoring of consumer satisfaction. 